\title{
FORMAÇÃO CONTINUADA NA IMPLEMENTAÇÃO DO ESPORTE EDUCAÇIONAL NA EDUCAÇÃO FÍSICA ESCOLAR
}

\author{
Ana Luiza Barbosa Anversa \\ Universidade Estadual de Maringá, Maringá, Paraná, Brasil \\ Vânia de Fátima Matias de Souza \\ Universidade Estadual de Maringá, Maringá, Paraná, Brasil \\ Luciane Cristina Arantes da Costa \\ Universidade Estadual de Maringá, Maringá, Paraná, Brasil \\ Amauri Aparecido Bássoli de Oliveira \\ Universidade Estadual de Maringá, Maringá, Paraná, Brasil
}

\begin{abstract}
Resumo
Considerando o processo de formação continuada no campo da Educação Física, encontramos em destaque reflexões sobre o esporte educacional e sua ação pedagógica no contexto escolar. O presente trabalho apresenta o resultado da análise desse contexto a partir do processo de formação continuada e implementação do esporte educacional por meio da experiência de professores da rede estadual de ensino no estado de Sergipe, Brasil. Os resultados indicam a relevância do processo formativo para a construção de um planejamento cuja aplicabilidade se dá no sentido de oportunizar a prática do esporte educacional enquanto elemento da cultura, potencializando ações coletivas que rompem com a linearidade técnica-instrumental, e valorizando a relação atitudinal, conceitual e procedimental por meio do esporte.

Palavras-chave: Educação Física Escolar. Formação Continuada. Esporte Educacional.

\section{CONTINUING EDUCATION ON THE ESTABLISHMENT OF EDUCATIONAL SPORT ON SCHOLAR PHYSICAL EDUCATION}

\begin{abstract}
Considering the process of continuing education on physical education, we have found worth mentioning some reflections about the educational sport and its pedagogic activity in the scholar background. Thus, the current study presents the result of a deep analysis of this aforementioned background through the continuing education process and the establishment of educational sport by means of teachers' experience from public schools located in the state of Sergipe, Brazil. The results show the relevance of the continuing education process for the development of a planning whose applicability may optimize the practice of educational sport as a meaningful culture element, promoting collective actions and disrupting the technicalinstrumental linearity. Additionally, the attitudinal, conceptual and proceeding relationships may be enriched through sport.
\end{abstract}

Keywords: Scholar physical education. Continuing education. Educational Sport. 


\title{
FORMACIÓN CONTINUADA EN LA IMPLEMENTACIÓN DEL DEPORTE EDU- CACIONAL EN LA EDUCACIÓN FÍSICA ESCOLAR
}

\begin{abstract}
Resumen
Considerando el proceso de formación continuada en el campo de la Educación Física, encontramos en destaque reflexiones sobre el deporte educacional y su acción pedagógica en el contexto escolar. Este trabajo presenta el resultado del análisis de ese contexto a partir del proceso de formación continuada e implementación del deporte educacional por medio de la experiencia de profesores de la red estadual de enseñanza en el estado de Sergipe-Brasil. Los resultados indican la relevancia del proceso formativo para la construcción de una planificación cuya aplicabilidad acontece para dar la oportunidad de practicar el deporte educacional como elemento de la cultura, potenciando acciones colectivas que rompen con la linealidad técnicainstrumental, valorizando la relación actitudinal, conceptual y procedimental por medio del deporte.
\end{abstract}

Palabras clave: Educación Física Escolar. Formación continua. Deporte educacional.

\section{Introdução}

O esporte historicamente compõe o acervo de temas da Educação Física Escolar e, por vezes, constituiu-se como sinônimo desse componente curricular, tendo em vista sua vinculação e grau de importância. Nesse sentido, o esporte tem sido frequentemente refletido no campo das práticas pedagógicas com foco na qualidade do ensino das aulas de Educação Física Escolar. Com destaque, há que se mencionar a existência de um movimento no campo educacional com vistas a ações docentes que busquem o rompimento com a linearidade proveniente da racionalidade técnica instrumental vinculada tradicionalmente ao campo do esporte, tendo como perspectiva a ação pedagógica sustentada no esporte educacional (BAYER, 1994; GRECO, 1998; KUNZ, 2001; CARLAN; KUNZ; FENSTERSEIFER, 2012; SANTOS, 2015).

Destaca-se que a compreensão do trato com o esporte educacional inserido no campo escolar se dá pelo entendimento de que o esporte educacional está vinculado à dimensão do esporte-educação, cujo enfoque, segundo Tubino (2005, p. 43), se dá pela concepção do esporte escolar sem fins competitivos, tendo como destaque os princípios de "inclusão, participação, cooperação, coeducação e corresponsabilidade".

Tubino (2005) ressalta que a mudança do pensamento e do foco do esporte foi ocasionada na sociedade moderna a partir da Carta Internacional de Educação Física e Esporte da UNESCO em 1978, na qual o esporte passa a atender especificações distintas, ou seja, passa a adotar as dimensões:

Esporte-Educação, o Esporte-Lazer e o Esporte de Desempenho. Nessa perspectiva o Esporte-Educação é guiado pelos princípios sócio-educativos da participação, cooperação, coeducação, corresponsabilidade, da inclusão, do desenvolvimento esportivo e do desenvolvimento do espírito esportivo (TUBINO, 2005, p. 100).

A implementação dessa propositiva do esporte-educação no contexto escolar tem se dado lentamente, havendo ainda questionamentos acerca do papel educativo do esporte (CARLAN et al., 2012). Esse fato pode estar atrelado à estrutura da formação do profissional da Educação Física. Contudo, entende-se que no contexto escolar, cabe "ao profissional da Educação Física proporcionar, pela tematização do seu conteúdo específico, uma compreensão crítica das práticas esportivas, potencializando os sujeitos a estabelecer vínculos com o contexto sociocultural em que estão inseridos" (KUNZ, 2001, p. 73). 
Nesse sentido, passa-se a evidenciar outras necessidades para a implementação e aceitação do trabalho educativo com foco no esporte-educação. A formação continuada tem se constituído em um exponencial nos debates acerca da qualidade do ensino da Educação Física Escolar, se colocando como uma das possibilidades de se legitimar a ação identitária do esporte-educação na escola, haja vista que esta se constitui em ações reflexivas sobre as questões pedagógicas e reflete o cotidiano da prática docente para além do saber-fazer do professor.

Afinal, o saber docente se refere ao conjunto de saberes construído a partir das relações culturais e sociais estabelecidas nos diversos contextos de formação do sujeito, isso porque, segundo Tardif (2002), a construção do saber é um processo plural heterogêneo, temporal, que se constrói durante a vida e o decurso da carreira; logo, é personalizado, situado. Assim, essa concepção dos conhecimentos que alicerçam as ações interventivas do professor se faz necessária para que sua atuação no contexto escolar esteja centrada na práxis coletiva, trazendo a diversidade de conhecimentos e contribuindo para a ampliação das possibilidades e construção de novos saberes.

Tardif (2002) reitera ainda que o saber docente se origina da formação profissional, do conjunto de saberes transmitido pelas instituições de formação de professores; dos saberes disciplinares, que correspondem aos diversos campos de conhecimento e que emergem da tradição cultural; curriculares, advindos dos programas escolares e experienciais, esses advindos do trabalho cotidiano do profissional; logo, o contexto escolar é um espaço de interação no qual ocorre a mobilização desses saberes, ou seja, a transmissão de uma ideia de movimento, de construção, que esteja em constante renovação, com valorização da diversidade de saberes presentes no contexto escolar, o que acaba se replicando com ênfase no desenvolvimento das aulas com foco no esporte educacional.

De acordo com Sadi (2004), intervir com o esporte no universo escolar requer considerar as relações socioculturais e humanas presentes nesse ambiente. Nesse contexto, é preciso considerar que a ação profissional, no campo do esporte educacional, leva o professor a deparar-se com múltiplas situações, as quais irão requerer que a ação interventiva seja focada no processo de diálogo com a situação, possibilitando a construção de novas formas e perspectivas de perceber e reagir. Segundo Shön (1992), a criação e construção de uma nova realidade obrigam o professor a ir além das regras, fatos, teorias e procedimentos conhecidos e disponíveis, reestruturando a concepção da realidade com que se depara.

Essa reconstrução dos saberes e conhecimentos se dá efetivamente na realidade do contexto escolar, por meio da articulação entre a prática docente e a realidade social, isso porque é na aula que se pressupõe que o professor tenha a dimensão da realidade tratada, e por meio da reflexão pedagógica é possível "diagnosticar o contexto de trabalho, tomar decisões, avaliar sua atuação e reconduzir suas ações sempre que necessário" (ZABALA, 1998, p. 10), provocando assim as mudanças necessárias. Evidente que essas mudanças dependerão das "características singulares de cada aluno, suas experiências, histórias de vida, capacidades e motivações", enfim, a diversidade na sala de aula deve ser entendida como o eixo estruturador do trabalho pedagógico; afinal, como afirma Freire (1996), o ser humano está sempre em construção, portanto há que se considerar que a educação é um processo permanente.

Kunz (1991) ressalta que a ação pedagógica também deve ser considerada uma ação política, uma vez que está atrelada ao contexto social-histórico em que está inserida, com sua concreta situação de ensino. Isso significa que, ao intervir a partir da perspectiva do esporte educacional, deve-se interpretar as intencionalidades dos educandos e educadores, inseridos em um contexto histórico social definido, refletindo intenções pedagógicas alicerçadas na visão de homem e de mundo do discurso educacional crítico adotado.

Nesse sentido, o trabalho docente no campo da Educação Física escolar, com foco no esporte educacional, deve ser considerado uma ação pedagógica, sustentada pela formação 
continuada, cujo repensar das práticas cotidianas esteja centrado numa perspectiva de ação formativa ativa, buscando romper com a fragmentação da cultura esportiva que, de acordo com Daólio (1998), impede a compreensão do esporte como produção humana dinâmica, dificultando a percepção da sua complexidade e diversidade culturais e congelando os significados sociais assumidos em diferentes momentos e lugares.

A partir da análise estabelecida entre a interlocução de autores, como Tardif (2002), Schön (1992), Pimenta (2006) e outros, observa-se que o processo de construção do profissional é uma relação que se estabelece por meio da interação e participação do sujeito na ação. Tendo essa compreensão, objetou-se na presente pesquisa analisar como um curso de formação continuada contribuiu para a ação docente com foco no esporte educacional.

\section{Caminho percorrido}

Entendendo que a ação formativa é um processo que se constitui a partir das relações entre os saberes historicamente produzidos e na busca por novos conhecimentos que podem ser transformados e reconfigurados de acordo com as necessidades de cada realidade, a presente pesquisa caracterizou-se como descritiva do tipo exploratória, de cunho quantiqualitativo (GIL, 2010). A obtenção dos dados se deu durante a formação continuada realizada pela Secretaria de Estado de Educação de Sergipe, em parceria com o Ministério do Esporte (ME), na perspectiva de capacitar e qualificar os professores que atuam nas escolas das redes públicas de ensino.

O critério de participação para compor a amostra da investigação se deu pela disponibilidade voluntária dos professores dispostos a discutir e refletir acerca das possibilidades de inserção do esporte educacional no espaço escolar a partir o curso ofertado. Assim, participaram 60 professores que integram a rede Estadual de Ensino, sendo 33 indivíduos do sexo masculino e 27 do sexo feminino, 63,3\% com idade média de 36 anos.

As questões centrais desta investigação centraram-se nos seguintes eixos: a) tempo de docência; b) conhecimento sobre a proposta do esporte educacional; c) contribuição da formação continuada; d) relevância das atividades desenvolvidas. Para a análise dos dados foi utilizado o software SPSS V. 21. Os dados qualitativos foram obtidos por meio de questionário estruturado e analisados por meio da categorização dos elementos coletados a partir dos indicadores de Bardin (2011). Para a apresentação dos recortes dos depoimentos dos participantes foi utilizada a nomenclatura P1, P2, P3 (...) P60.

O processo de capacitação se deu em dois momentos: primeiro, atividades na plataforma de cursos de Educação à Distância $(\mathrm{EaD})$ do Programa Segundo Tempo, e na sequencia, um encontro presencial. As atividades no ambiente on-line - plataforma $\mathrm{EaD}$, realizadas com duração de quatro semanas, centraram-se na inclusão digital dos professores envolvidos, sendo consideradas a exploração do Ambiente Virtual de Aprendizagem, o momento de leitura e a reflexão interativa acerca dos pressupostos do esporte educacional a partir dos fóruns temáticos e grupos de atividades propostas on-line, com textos e vídeos sugeridos. Na etapa presencial, realizada em dois dias consecutivos, são trabalhas atividades práticas sugeridas nas obras "Práticas Corporais". Esse momento tem por objetivo refletir sobre a possibilidades do trato das práticas corporais sob a perspectiva dos esportes educacionais. (OLIVEIRA; DARIDO; GONZÁLES, 2014; DARIDO; OLIVEIRA; GONZÁLES, 2014; GONZÁLES; DARIDO; OLIVEIRA, 2014).

Por fim, destaca-se que o projeto está vinculado ao Projeto de Pesquisa "Acompanhamento Pedagógico do PST", de abrangência nacional, aprovado pelo Comitê Permanente de Ética em Pesquisa com Seres Humanos da Universidade Federal de Mato Grosso (processo ${ }^{\circ}$ 07312412.2.0000.5541-CEP/HUJM/UFMT). Todos os participantes foram informados sobre as questões do estudo, preenchendo o Termo de Consentimento Livre e Esclarecido (TCLE). 


\section{Formação Continuada com foco no esporte educacional e os reflexos no cotidiano esco- lar}

Sabe-se que o ingresso na carreira docente é um desafio para os profissionais na área de Educação Física, uma vez que é nas ações do cotidiano escolar que os professores se deparam com a necessidade de corresponder à sua expectativa e à da comunidade escolar (VENTORIM; POZZATTI, 2012). A implementação do Esporte Educacional no cotidiano escolar demanda formação continuada de professores, reflexões sobre as possibilidades do esporte e o fortalecimento de vínculos interinstitucionais, agregando valores na ação e na tríade do ensino superior (ensino, pesquisa e extensão) sob perspectiva de uma ação com responsabilidade social (LORENZINI; SANTOS, 2009).

Ao identificar o momento da carreira dos participantes da pesquisa, pode-se constatar que em relação ao tempo de atuação com a docência na Educação Física escolar, o grupo apresentou-se com ampla diversidade, sendo que 25 participantes $(41,7 \%)$ encontram-se no ciclo de entrada na carreira, com idades variando entre 19 a 54 anos, fato este que ressalta as mudanças ocorridas nos currículos de formação, nas expectativas e motivações pessoais para com o trabalho docente e com o trato do esporte educacional aplicado às aulas de Educação Física na educação básica.

Quando questionados acerca dos cursos de formação continuada com foco no Esporte Educacional ofertados pelo Ministério do Esporte, 4, 7\% dos participantes afirmaram desconhecer os cursos e propostas de formação continuada com esse enfoque. Com relação ao nível de satisfação em relação à contribuição da formação continuada ofertada, aproximadamente 92\% (54 participantes) dos professores afirmaram estar satisfeitos em relação à essa contribuição para o aprimoramento de sua ação docente com relação ao planejamento, estruturação e organização das aulas a partir dos pressupostos desse modelo de ensino.

Com relação às contribuições das discussões teórico-prático, que tratam dos conceitos, princípios e delineamentos das aulas no modelo do Esporte Educacional, verificou-se a partir dos relatos dos participantes que o processo de capacitação possibilitou a aproximação da teoria proposta do referencial utilizado com as demandas cotidianas da profissão. Os participantes relatam que:

[...] A capacitação atendeu às necessidades principais para se trabalhar a Educação Física, deixando a possibilidade de exploração de conteúdos novos e significativos (P 7)

[...] a capacitação foi muito bem planejada, contemplando os conteúdos dos módulos, favorecendo o entendimento das atividades e sua aplicabilidade (P 3);

A materialização do conteúdo foi condizente com os princípios abordados nos livros (P 30);

Os livros didáticos e as explanações de como poderiam ser trabalhados (P 15);

A prática fez entender perfeitamente a teoria, com isso facilitou a aprendizagem do conteúdo (P 16);

Os professores tiveram muito o foco de explanar todas as vivências do EAD, com os livros (Coleção Práticas Corporais) em mãos para ilustrar e nos perguntando (P 14).

Com relação à oficina de experimentação, vivência e prática com o Esporte Educacional, ocorrida após os estudos teóricos dos conceitos, estrutura e ações desencadeadas na etapa $\mathrm{EaD}, 86 \%$ dos participantes afirmaram estar satisfeitos durante a formação continuada, alegando a compreensão e organização das aulas nessa perspectiva a partir da compreensão teorico-prática de sua implementação.

Das ações desenvolvidas, 33,3\% dos participantes destacaram a relevância da reflexão sobre a ação docente, evidenciando na sequência os aspectos pedagógicos e metodológicos 
para a implementação, planejamento e organização da Educação Física Escolar a partir da perspectiva do Esporte Educacional. Em relação às propostas pedagógicas de trabalho com o Esporte Educacional tratadas na formação continuada ofertada, evidenciou-se a compreensão dos participantes como sendo uma possibilidade de superação dos modelos tradicionais no processo de ensino e aprendizagem, evidenciando sua aplicabilidade no ambiente escolar. Conforme exposto pelos participantes sobre a formação continuada:

Repensar e inovar as nossas metodologias, construir práticas pedagógicas de acordo com a realidade em que atuamos é muito importante para o processo ensinoaprendizagem da EF escolar (P 2);

A capacitação trouxe possibilidades de intervenção que se adequam à realidade escolar, e fomenta a prática pedagógica (P 3);

Por mostrar passo a passo os caminhos pedagógicos a serem seguidos (P 39);

A relação entre as duas etapas (EaD e presencial) foram bem importantes para perceber a aplicabilidade da teoria (P 17);

A etapa EaD foi muito importante, estudando o teórico e pondo em prática no presencial, foi um momento de discussão e reflexão (P 32);

A plataforma EaD introduz provocações e debates iniciais e o momento presencial fortalece as dimensões pedagógicas (P 48).

Os depoimentos vão ao encontro das reflexões realizadas no meio acadêmico acerca da necessidade de processos de formação continuada que tratam dos conhecimentos necessários para a prática cotidiana escolar, os quais devem ser estruturados adequadamente com subsídios tanto no campo teórico, quanto no prático (GRAÇA, 1997; PACHECO; FLORES, 1999; SHULMAN, 1986).

De acordo com Oliveira e Perim (2009), a formação continuada deve oportunizar aos professores vivências por meio de exemplos teórico-práticos do esporte na perspectiva da cooperação, para a compreensão das dimensões dos conteúdos: "o que se deve saber?" (dimensão conceitual), "o que se deve saber fazer?" (dimensão procedimental) e "como se deve ser?" (dimensão atitudinal). Fato que foi evidenciado pelos professores ao mencionarem que:

As dimensões atitudinal, procedimental e conceitual foram apresentadas de forma mais coerente, demonstrnado como se trabalhar com os conteúdos da Educação Física (P15);

As atividades são organizadas de forma inicial a fazer o aluno participar conceitualmente nas atividades propostas (P 30);

[...] a formação contribui para aumentar o meu conhecimento de vários tipos de esportes nas três dimensões: conceitual, atitudinal e procedimental (P 41);

Foi muito focado a questão dos processos procedimental, conceitual e atitudinal, mostrando na prática das atividades a importância de cada uma [...] (P 58).

Com relação às fragilidades do processo de formação, os professores participantes evidenciaram a questão do tempo/duração, mas, segundo eles, o aprendizado foi significante para a sua ação docente, no contexto do cotidiano escolar, sendo salientada a necessidade de ampliação do tempo/período destinado às vivências e experimentações com foco no desenvolvimento do planejamento e aplicação das aulas, seguindo os princípios do esporte educacional, conforme descrito por P17 ao afirmar que: "como sempre o tempo é que não permitiu mais aprofundamento dos conteúdos, bem como da reconstrução ou construção de planos de aula que poderia ser desenvolvida." Observa-se a partir dos relatos a carência e a necessidade de ampliação de ofertas de cursos de capacitação e formação continuada, direcionada ao trabalho docente com foco no esporte educacional. 


\section{Considerações finais}

Ao analisar o curso de formação continuada ofertado aos professores da rede pública do estado de Sergipe, realizado e ofertado pelo Programa Segundo Tempo/ME, tendo como foco a ação pedagógica das aulas de Educação Física Escolar centradas nos princípios do esporte educacional, evidenciou-se a carência docente no processo formativo com foco em uma intervenção docente sustentada nos pressupostos do esporte educacional.

A ação desenvolvida evidenciou que as iniciativas decorrentes do formato de capacitação e/ou formação continuada são entendidas como necessárias pelos docentes para a mudança na prática cotidiana no contexto escolar, haja vista que os participantes do estudo destacaram o fato de que por meio dos conteúdos organizados durante experiência com o esporte educacional, tendo exemplos teórico-práticos, foi auxiliada a compreensão das dimensões dos saberes e dos conhecimentos tratados no ambiente escolar.

\section{Referências}

BARDIN, Laurence. Análise de conteúdo. Lisboa: Edições 70, 2011.

BAYER, Claude. O ensino dos desportos colectivos. Lisboa: Dinalivro, 1994.

CARLAN, Paulo; KUNZ, Elenor; FENSTERSEIFER, Paulo Evaldo. O esporte como conteúdo da Educação Física escolar: estudo de caso de uma prática pedagógica "inovadora". Movimento, v. 18, n. 4, p. 55-75, out/dez, 2012.

DARIDO, Suraya Cristina; OLIVEIRA, Amauri Aparecido Bássoli de; GONZÁLEZ, Fernando Jaime. Coleção Práticas Corporais e a Organização do Conhecimento. Ginástica, Dança e Artes Circenses. 2014a. v 3.

Coleção Práticas Corporais e a Organização do Conhecimento. Lutas, Capoeira e Práticas Corporais de Aventura. 2014b. v. 4.

FREIRE, P. Pedagogia da Autonomia: Saberes necessários à prática educativa. 33. ed. São Paulo: Paz e Terra, 1996.

GIL, Antonio Carlos. Como Elaborar Projetos de Pesquisa. 5. ed. São Paulo: Atlas, 2010.

GONZÁLEZ, Fernando Jaime; DARIDO, Suraya Cristina; OLIVEIRA, Amauri Aparecido Bássoli de (Org.). Práticas corporais e a organização do conhecimento: esportes de marca e com rede divisória ou muro/parede de rebote: badminton, peteca, tênis de campo, tênis de mesa, voleibol, atletismo. Maringá: Eduem, 2014.

GRAÇA, A. O conhecimento pedagógico do conteúdo no ensino do basquetebol. $331 \mathrm{f}$. Doutorado em Ciências do Desporto. Faculdade de Desporto, Universidade do Porto, $1997 .$.

GRECO, Plabo Juan (Org.). Metodologia da iniciação esportiva na escola e no clube: Iniciação esportiva universal. Belo Horizonte: UFMG, 1998.

KUNZ, Elenor. Educação Física: ensino \& mudanças. Íjuí: Editora Unijuí, 1991. 
Transformação didático-pedagógica do esporte. Ijuí: Ed. da Unijuí, 2001.

LORENZINI, Ana Rita; SANTOS, Ana Lúcia Félix dos. Programa Segundo Tempo no Agreste de Pernambuco: uma experiência interinstitucional e interdisciplinar. In: Congresso Brasileiro de Ciências do Esporte e III Congresso Internacional de ciência do Esporte. 2009. Anais... Salvador, 2009, p. 1-13.

OLIVEIRA, Amauri Aparecido Bássoli; PERIM, Gianna Lepre. Fundamentos Pedagógicos do Programa Segundo Tempo: da reflexão à prática. Maringá: Eduem, 2009.

OLIVEIRA, Amauri Aparecido Bássoli de; DARIDO, Suraya Cristina; GONZÁLEZ, Fernando Jaime (Org.). Práticas corporais e a organização do conhecimento: esportes de invasão: basquetebol, futebol, futsal, handebol, ultimate frisbee . Maringá: Eduem, 2014.

PACHECO, José Augusto; FLORES, Maria Assunção. Formação e avaliação de professores. Porto, Portugal: Porto Editora, 1999.

PIMENTA, Selma Garrido et al. Saberes pedagógicos e atividade docente. 4. ed. Rio de Janeiro: Vozes, 2006.

SADI, Renato. Sampaio. Pedagogia do esporte. Brasília: Ed. da UNB; MEC, 2004.

SANTOS, Juliana Lodder Martins dos. Análise da produção acadêmica sobre o esporte educacional no Brasil: contribuições para a educação física escolar. 2015. 24 f. Trabalho de conclusão de curso (Licenciatura - Educação Física) - Universidade Estadual Paulista, Instituto de Biociências de Rio Claro, 2015.

SCHÖN, Donald. Formar professores como profissionais reflexivos. In: NÓVOA, A. (Org.). Os professores e sua formação. Lisboa: Dom Quixote, 1992. p. 79-91.

SHULMAN, Lee. Those who understand: knowledge growth in teaching. Educational Researcher, Washington, v. 15, n. 2, p. 4-14. 1986.

VENTORIM, Silvana; POZZATTI, Mariana. Trabalhadores docentes do Espírito Santo: identidades e processos de formação. In: BARTOLOZZI, Eliza; OLIVEIRA, Dalila A; VIEIRA, Lívia F. (Org.). O trabalho docente na educação básica: o Espírito Santo em questão. Belo Horizonte: Fino Traço, 2012. p. 81-102.

TARDIF, Maurice. Saberes docentes e formação profissional. 6. ed. Petrópolis: Vozes, LTDA, 2002.

TUBINO, Manoel Gomes. Educação Física e o Esporte do Ocidente no século XX. Arquivos em Movimento, Rio de Janeiro, v. 1, n. 2, p. 99-100, jul./dez. 2005.

ZABALA, Antonio. A Prática Educativa: como Ensinar. Trad. Ernani F da Rosa. Porto Alegre: Artmed, 1998. 
Recebido em: 27/12/2017

Revisado em: 29/01/2018

Aprovado em: 09/02/2018

Endereço para correspondência:

ana.beah@gmail.com

Ana Luiza Barbosa Anversa

Universidade Estadual de Maringá, Centro de Ciências Biológicas, Departamento de Educação Física. Av. Colombo, 5790 - Campus Universitário - Dep. de Educação Física

Zona Sete

87020900 - Maringá, PR - Brasil 